\title{
Phytochemical Contents and Antioxidant and Antiproliferative Activities of Selected Black and White Sesame Seeds
}

\author{
Lin Zhou, ${ }^{1,2}$ Xiaohui Lin, ${ }^{2}$ Arshad Mehmood Abbasi, ${ }^{2,3}$ and Bisheng Zheng ${ }^{2}$ \\ ${ }^{1}$ Guangdong Province Key Laboratory for Biotechnology Drug Candidates, School of Biosciences and Biopharmaceutics, \\ Guangdong Pharmaceutical University, Guangzhou 510006, China \\ ${ }^{2}$ School of Light Industry and Food Sciences, South China University of Technology, Guangzhou 510641, China \\ ${ }^{3}$ Department of Environmental Sciences, COMSATS Institute of Information Technology, Abbottabad 22060, Pakistan \\ Correspondence should be addressed to Lin Zhou; zhoulin@gdpu.edu.cn
}

Received 15 April 2016; Revised 7 June 2016; Accepted 30 June 2016

Academic Editor: Michael D. Coleman

Copyright ( 2016 Lin Zhou et al. This is an open access article distributed under the Creative Commons Attribution License, which permits unrestricted use, distribution, and reproduction in any medium, provided the original work is properly cited.

\begin{abstract}
Sesame (Sesamum indicum L.) seeds are popular nutritional food but with limited knowledge about their antioxidant and antiproliferative activities of various varieties. Phytochemical profiles and antioxidant and antiproliferative activities of six varieties of sesame (Sesamum indicum L.) seeds were studied. Fenheizhi3 (black) cultivar exhibited the maximum contents of total phenolics and lignans and values of total oxygen radical absorbance capacity (ORAC) and antiproliferative activity $\left(\mathrm{EC}_{50}\right)$ against $\mathrm{HepG}_{2}$ cells. Bound ORAC values showed strong associations with bound phenolics contents $(r=0.976, p<0.01)$; in bound phenolic extracts, $\mathrm{EC}_{50}$ values showed strong negative associations with phenolic contents $(r=-0.869, p<0.05)$ and ORAC values $(r=-0.918, p<0.01)$. Moreover, the contents of free phenolics were higher than that of the bound phenolics, and the three black sesame seeds generally depicted higher total phenolics compared to the three white varieties. The antioxidant (ORAC values) and antiproliferation activities of six sesame seeds were both associated with contents of bound phenolics $(r>0.8, p<0.05)$. Interestingly, nonlignan components in bound phenolics contributed to the antioxidant and antiproliferative activities. This study suggested that Fenheizhi3 variety is superior to the other five varieties as antioxidant supplements.
\end{abstract}

\section{Introduction}

Sesame "Sesamum indicum L." is a commonly growing plant species mainly in tropical and subtropical regions of the world, particularly in Burma, India, China, and Sudan [1]. Sesame seeds are preferably used along with bread, biscuits, crackers, and so forth and as seasoning in food around the world [2]. Sesame seeds are important sources of oil, protein, carbohydrates, and minerals for human nutrition [3].

Sesame seeds color varied from cream-white to charcoalblack, whereas white and black are the typical skin color. Black sesame seed is superior to white one as food for health in traditional beliefs of Asian countries and is included in Pharmacopoeia of the People's Republic of China (PPRC, 2015) as liver and kidney benefiting traditional Chinese medicine (TCM). It has been reported that the seed colors of sesame affect the phytochemical contents and their biological activities $[4,5]$. Phytochemical compounds in sesame seed such as sesamin, sesamol, and anthrasesamone $\mathrm{F}$ have been proved to have in vitro/in vivo antioxidant and antiaging activity [6-9]. Moreover, sesamin and sesamolin showed anti-inflammatory, antihypertensive, and anticarcinogenic effects in numerous studies [10-12].

The common nutritional evaluations of sesame seeds are based on the contents of proteins, oils, and lignans. However, little work was conducted on the correlations between multicomponents and antioxidant activity and multicomponents and antiproliferative activity in various sesame seeds varieties. Therefore, the phytochemical profiles including the contents of phenolics, flavonoids, and lignans, in vitro antioxidant activities, and antiproliferative activities against HepG2 cells of six varieties of sesame seeds in China were studied in the present work. Particularly, the six sesame seeds (three of black and three of white skin color, nonscaled planting) are newly bred varieties in midwest of China for improved nutrition values. The knowledge of the antioxidant 
and antiproliferative activities of various sesame seeds will benefit the sesame seed planters, relevant manufacturers, and ordinary consumers.

\section{Materials and Methods}

2.1. Chemicals and Materials. Methanol (MeOH), ethanol $(\mathrm{EtOH}), \mathrm{n}$-hexane, ethyl acetate, hydrochloric acid $(\mathrm{HCl})$, and acetic acid (HAC) were purchased from Guanghua Sci-Tech Co., Ltd. (Guangdong, China). Potassium chloride $(\mathrm{KCl})$, sodium acetate $(\mathrm{NaAC})$, sodium carbonate $\left(\mathrm{NaCO}_{3}\right)$, sodium hydroxide $(\mathrm{NaOH})$, potassium phosphate monobasic $\left(\mathrm{KH}_{2} \mathrm{PO}_{4}\right)$, and potassium phosphate dibasic $\left(\mathrm{K}_{2} \mathrm{HPO}_{4}\right)$ were of analytical grade and were purchased from Sangon Biotech Co., Ltd. (Shanghai, China). 2,2'-Azobis(2-amidinopropane) dihydrochloride (ABAP), $2^{\prime}, 7^{\prime}$-dichlorofluorescin diacetate (DCFH-DA), fluorescein disodium salt, catechin hydrate (HPLC, $\geq 98 \%$ ), Folin-Ciocalteu reagent, ascorbic acid, 6-hydroxy-2,5,7,8-tetramethylchroman-2-carboxylic acid (Trolox), formic acid (chromatographic grade), and methanol (chromatographic grade) were purchased from SigmaAldrich, Inc. (St. Louis, MO, USA). Trifluoroacetic acid (TFA, analytical grade) and aluminum chloride $\left(\mathrm{AlCl}_{3} \cdot 6 \mathrm{H}_{2} \mathrm{O}\right.$, analytical grade) were purchased from Fisher Scientific (Fair Lawn, NJ, USA). Sodium borohydride $\left(\mathrm{NaBH}_{4}\right.$, reagent grade), chloranil (analytical grade), vanillin (analytical grade, 99\%), and gallic acid (analytical grade, 99\%) were purchased from Aladdin, Inc. (Shanghai, China). Sesamol, sesamolin, and sesamin (HPLC, $\geq 98 \%$ ) were purchased from Chengdu Pufei De Biotech Co., Ltd. (Sichuan, China). HepG2 human liver cancer cells were purchased from American Type Culture Collection (Rockville, MD, USA). WME medium, foetal bovine serum (FBS), insulin, and other cell culture reagents were purchased from Gibco Life Technologies Co. (Grand Island, NY, USA). Six sesame seed varieties (three black and three white) were kindly donated by Shanxi Academy of Agricultural Sciences (Taiyuan city, China), which were harvested in 2014 and stored in desiccator at room temperature until analysis.

2.2. Moisture Content. The moisture content was analyzed by oven-dry method [13]. Briefly, $1 \mathrm{~g}$ of sample was dried in electric oven at $105^{\circ} \mathrm{C}$ to a constant weight and moisture content was expressed as percent of dry weight (DW) in triplicate.

\subsection{Phenolics Extraction and Determination}

2.3.1. Free Phenolics Extraction. Free phenolic compounds were extracted using the modified method reported previously [14]. Briefly, $1 \mathrm{~g}$ of sesame seed was blended with $5 \mathrm{~mL}$ of hexane for $1 \mathrm{~min}$. After centrifugation at $2700 \times \mathrm{g}$ for $3 \mathrm{~min}$, residue was defatted two more times. Add $10 \mathrm{~mL}$ of $80 \%$ chilled acetone to the residue and blend $1 \mathrm{~min}$. The supernatant was collected after being centrifuged at $2700 \times \mathrm{g}$ for $3 \mathrm{~min}$, repeated twice. The supernatant was pooled and evaporated to dryness at $45^{\circ} \mathrm{C}$ under vacuum. The solution was reconstituted in $10 \mathrm{~mL}$ of $70 \%$ methanol and free phenolic extracts $\left(100 \mathrm{mg} \mathrm{mL}^{-1}\right)$ were stored at $-40^{\circ} \mathrm{C}$ until analysis.

2.3.2. Bound Phenolics Extraction. Bound phenolics were extracted using the method described by Chen et al. [14] with modifications. Briefly, the residues obtained after extraction of free phenolics were flushed with nitrogen gas for $2 \mathrm{~min}$, sealed, and digested with $20 \mathrm{~mL}$ of $4 \mathrm{M} \mathrm{NaOH}$ at room temperature for $1 \mathrm{~h}$. The mixture was neutralized with $10 \mathrm{M}$ concentrated $\mathrm{HCl}$. Then $20 \mathrm{~mL}$ hexane was added to extract residual lipids in the mixture for $10 \mathrm{~min}$ (not necessary if no residual lipids). After centrifuging at $2700 \times \mathrm{g}$ for $5 \mathrm{~min}$, remaining residues were extracted five times with ethyl acetate. The ethyl acetate fractions were pooled and evaporated to dryness at $45^{\circ} \mathrm{C}$ under vacuum. The bound phenolics were reconstituted to $10 \mathrm{~mL}$ of $70 \%$ methanol and bound phenolic extracts $\left(100 \mathrm{mg} \mathrm{mL}^{-1}\right)$ were stored at $-40^{\circ} \mathrm{C}$ until analysis.

2.3.3. Determination of Total Phenolic Contents. Total phenolic contents of each sample were determined using the modified Folin-Ciocalteu colorimetric method [14, 15]. Briefly, free phenolic and bound phenolic extracts were diluted 1020 times with distilled water and were reacted with FolinCiocalteu reagent and then neutralized with $\mathrm{Na}_{2} \mathrm{CO}_{3}$. After 90 min incubation, the absorbance of the resulting solution was recorded at $760 \mathrm{~nm}$ using MRX II Dynex plate reader (Dynex Technologies Inc., Chantilly, VA, USA). Total phenolic contents were expressed as grams of gallic acid equivalents per $\mathrm{kg}$ of sample on DW ( $\mathrm{g} \mathrm{GAE} \mathrm{kg}^{-1}$ ).

2.4. Determination of Total Flavonoid Contents. Total flavonoid contents were determined by sodium borohydridechloranil (SBC) protocol [16]. Briefly, $1 \mathrm{~mL}$ of free and $1 \mathrm{~mL}$ of bound phenolic extracts were added to test tubes $(15 \times$ $150 \mathrm{~mm}$ ) and were dried under nitrogen gas. The residues and catechin hydrate standards $(0.1-10.0 \mathrm{mM})$ were prepared in $1 \mathrm{~mL}$ of THF/EtOH $(1: 1, \mathrm{v} / \mathrm{v})$. Extracts or standard solution was mixed with $0.5 \mathrm{~mL}$ of $50 \mathrm{mM} \mathrm{NaBH}_{4}$ solution and $0.5 \mathrm{~mL}$ of $74.6 \mathrm{mM} \mathrm{AlCl}_{3}$ solution. After $30 \mathrm{~min}$ shaking in an orbital shaker at room temperature, $0.1 \mathrm{~mL}$ of $50.0 \mathrm{mM} \mathrm{NaBH}_{4}$ solution was added with continued shaking for $30 \mathrm{~min}$ at room temperature. $0.4 \mathrm{~mL}$ of cold $0.8 \mathrm{M}$ acetic acid solution was added and the mixtures were kept in the dark for $15 \mathrm{~min}$ after thorough mixing. $0.2 \mathrm{~mL}$ of $20.0 \mathrm{mM}$ chloranil was added and the mixture was heated at $95^{\circ} \mathrm{C}$ with shaking for $60 \mathrm{~min}$. Then, the reaction solutions were cooled using tap water and were brought to $1 \mathrm{~mL}$ using methanol. Afterward, $0.2 \mathrm{~mL}$ of $16 \%(\mathrm{w} / \mathrm{v})$ vanillin was added and mixed, followed by addition of $0.4 \mathrm{~mL}$ of $12 \mathrm{M} \mathrm{HCl}$ and the reaction solutions were kept in the dark for 15 min after thorough mixing. At last, the absorbance was recorded at $490 \mathrm{~nm}$ using MRX microplate reader with Revelation workstation (Dynex Technologies, Inc.). Total flavonoid contents were expressed as grams of catechin equivalents per $\mathrm{kg}$ of sample on $\mathrm{DW}$ $\left(\mathrm{gCE} \mathrm{kg}^{-1}\right)$. 
TABLE 1: Description and moisture contents of six sesame seeds varieties.

\begin{tabular}{lccccr}
\hline Varieties & Abbreviation & Harvest year & Color & Origin & Moisture content (\%) \\
\hline Zhenzhou1 & B1 & 2014 & Black & Zhenzhou, Henan & $1.63 \pm 0.13$ \\
Fenheizhi3 & B2 & 2014 & Black & Agriculture academy of Shanxi & $5.14 \pm 0.09$ \\
05H27 & B3 & 2014 & Black & Shanxi Academy of Agricultural Sciences & $5.22 \pm 0.01$ \\
Jizhi157 & W1 & 2014 & White & Hebei & $4.50 \pm 0.14$ \\
Fenzhi2 & W2 & 2014 & White & Shanxi & $4.63 \pm 0.13$ \\
Jizhi1 & W3 & 2014 & White & Shanxi Academy of Agricultural Sciences & $4.63 \pm 0.03$ \\
\hline
\end{tabular}

Data were reported as mean $\pm \mathrm{SD}$.

2.5. Estimation of Lignan Contents. Both the free and bound phenolic extracts $\left(100 \mathrm{mg} \mathrm{mL}^{-1}\right)$ were used for determination of lignan contents. The chromatographic analysis was performed to estimate lignan contents in sesame seeds as described by Reshma et al. [17] with some modifications. Briefly, three representative lignans (sesamol, sesamin, and sesamolin) were analyzed for the contents using Waters HPLC system (Waters Corp, Milford, MA) with a Waters $\mathrm{C}_{18}$ column $(5 \mu \mathrm{m}, 250 \mathrm{~mm} \times 4.6 \mathrm{~mm})$. The mobile phase consisted of methanol/water $(75: 25 \mathrm{v} / \mathrm{v})$ with $0.1 \%$ formic acid in water at a flow rate of $1 \mathrm{~mL} \mathrm{~min}^{-1}$. The $\mathrm{UV}$ detector was set at $290 \mathrm{~nm}$ with column temperature of $30^{\circ} \mathrm{C}$ and injection volume of $10 \mu \mathrm{L}$. Peak was identified by calibration standards of sesamol, sesamin, and sesamolin with a retention time of $3.4,8.3$, and $10.2 \mathrm{~min}$, respectively. The concentration range of standards of sesamol, sesamin, and sesamolin was from 2 to $200 \mu \mathrm{g} \mathrm{mL}^{-1}$ with recovery at $99.50 \pm 1.00 \%, 99.47 \pm 1.02 \%$, and $99.62 \pm 1.13 \%$, respectively. The results were expressed as milligrams per $\mathrm{kg}$ on DW $\left(\mathrm{mg} \mathrm{kg}^{-1}\right)$.

\subsection{Determination of Total Antioxidant Activity}

2.6.1. Oxygen Radical Absorbance Capacity (ORAC). ORAC values were determined using a Fluoroskan Ascent fluorescent spectrophotometer (Molecular Devices, Sunnyvale, CA) $[18,19]$. Briefly, $20 \mu \mathrm{L}$ extracts $\left(100 \mathrm{mg} \mathrm{mL}^{-1}\right)$ or Trolox was mixed with $200 \mu \mathrm{L}$ of fluorescein and incubated at $37^{\circ} \mathrm{C}$ for $20 \mathrm{~min}$, followed by adding $20 \mu \mathrm{L}$ of freshly prepared $119.4 \mathrm{mM}$ ABAP into black walled 96-well plates. Fluorescence intensity was recorded automatically at $37^{\circ} \mathrm{C}$, excitation of $485 \mathrm{~nm}$, and emission of $535 \mathrm{~nm}$ for 35 cycles every $5 \mathrm{~min}$. Final values of ORAC were expressed as micromoles of Trolox equivalents (TE) per gram of sesame seeds on DW basis $\left(\mu \mathrm{mol} \mathrm{TE} \mathrm{g}{ }^{-1} \mathrm{DW}\right)$.

2.6.2. Peroxyl Radical Scavenging Capacity (PSC). PSC values were determined by the method described by Adom and Liu [20]. Briefly, $100 \mu \mathrm{L}$ extracts $\left(100 \mathrm{mg} \mathrm{mL}^{-1}\right)$ or standards solutions (freshly prepared ascorbic acid solutions) were added in each well of the 96-well plate. Then, $100 \mu \mathrm{L}$ of DCFH dye $(13.26 \mu \mathrm{M})$, hydrolyzing with $1 \mathrm{mM} \mathrm{KOH}$ just before being used in the reaction, was also added. After adding $50 \mu \mathrm{L}$ of peroxyl radicals producer (ABAP, $40 \mathrm{mM}$ ), the mixtures were kept at $37^{\circ} \mathrm{C}$ for $40 \mathrm{~min}$. Fluorescent was dynamically recorded at excitation of $485 \mathrm{~nm}$ and emission of $538 \mathrm{~nm}$ using a multimode microplate reader (FilterMax
F5, Molecular Devices, USA). The results were calculated as micromoles of vitamin C equivalents (VCE) per gram of sesame seeds on DW basis $\left(\mu \mathrm{mol} \mathrm{VCE}{ }^{-1} \mathrm{DW}\right)$.

2.7. Determination of Antiproliferative Activity. The antiproliferative effects of sesame seeds extracts were assessed by modified methylene blue assay [21]. Briefly, HepG2 human liver cancer cell was grown in WME medium supplemented with 5\% FBS, $10 \mathrm{mM}$ N-2-hydroxyethylpiperazine- $\mathrm{N}^{\prime}$-2ethanesulfonic acid (HEPES), $2 \mathrm{mM} \mathrm{L}^{-1}$ glutamine, $5 \mathrm{~g} \mathrm{~mL}^{-1}$ insulin, $0.05 \mathrm{~g} \mathrm{~mL}^{-1}$ hydrocortisone, 50 units $\mathrm{mL}^{-1}$ penicillin, $50 \mathrm{~g} \mathrm{~mL}^{-1}$ streptomycin, and $100 \mathrm{~g} \mathrm{~mL}^{-1}$ gentamycin at $37^{\circ} \mathrm{C}$ and $5 \% \mathrm{CO}_{2}$ as described by Liu et al. [22]. HepG2 cells were cultured at a density of $2.5 \times 10^{4}$ cells/well in a 96well microplate with $100 \mu \mathrm{L}$ of growth medium. After $4 \mathrm{~h}$ of incubation at $37^{\circ} \mathrm{C}$, growth medium was displaced by $100 \mu \mathrm{L}$ of fresh medium containing $10-150 \mathrm{mg} \mathrm{mL}^{-1}$ of sesame seeds extracts. The wells containing fresh medium without extracts were set as the control. After $72 \mathrm{~h}$ of incubation, the number of the viable cells was counted by the methylene blue assay. The antiproliferative effects were assessed by the $\mathrm{EC}_{50}$ values and expressed as milligrams of sesame seeds extracts per milliliter.

2.8. Statistical Analysis. Statistical analysis was performed using SPSS software version 19.0 (LEAD Technologies, Inc., Chicago, IL). Variation of means was analyzed by ANOVA and Duncan's test. Significance of correlations was calculated by the Pearson coefficient. Dose-Effect analysis was performed using CalcuSyn software, version 2.0 (Biosoft, Cambridge, UK). Statistical significance was set at $p<$ 0.05 . All data were expressed as the mean \pm SD for three replications.

\section{Results and Discussion}

3.1. Moisture Content. Moisture content and description of six varieties of sesame seeds are given in Table 1. Except B1 variety, the average moisture content of the other five sesame seed varieties ranged from 4.36 to $5.23 \%$, which was consistent with the published data $[3,13]$. The possible reason for the lower moisture content in B1 variety was the moisture loss during storage before transportation. 


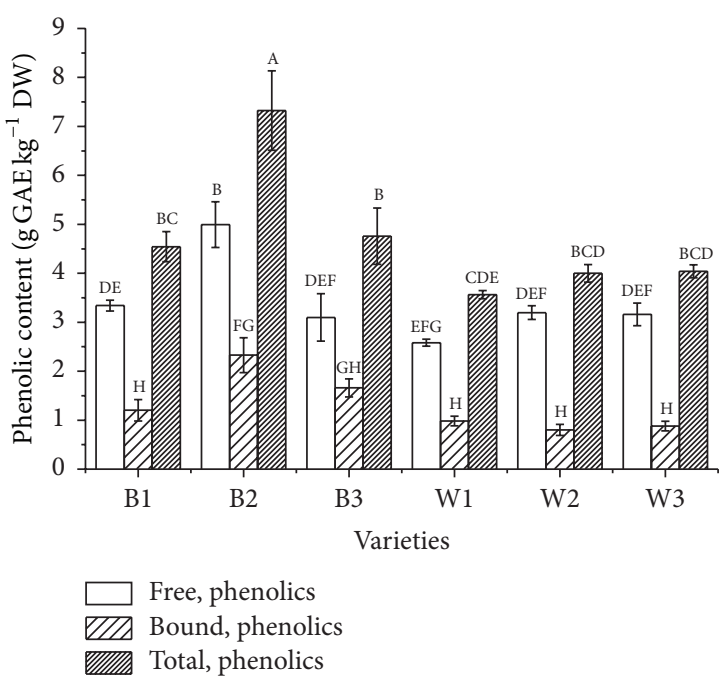

(a)

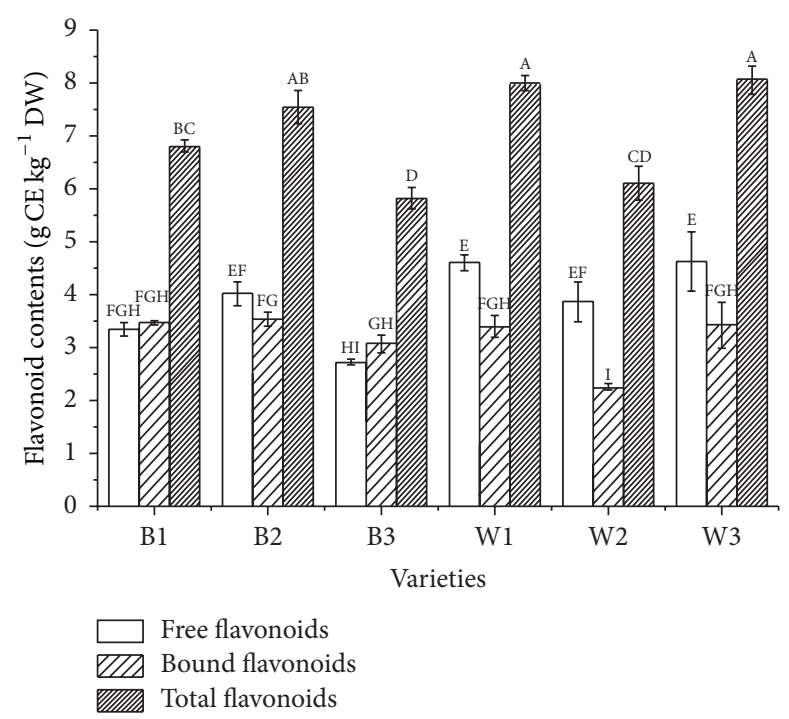

(b)

FIGURE 1: Free, bound, and total phenolic and flavonoid contents in six varieties of sesame seeds (B1, B2, B3, W1, W2, and W3). Bars with no letters in common are significant difference at $p<0.05$. (a) Phenolic contents. (b) Flavonoid contents.

\subsection{Phytochemical Composition of Selected Sesame Seeds}

3.2.1. Contents of Phenolics and Flavonoids. Measured levels of total phenolic and total flavonoid contents of six sesame seed varieties were presented in Figures 1(a) and 1(b). From Figure 1(a), free phenolic contents were higher than that of the bound phenolic. Black sesame seed variety B2 exhibited maximum free and bound phenolics (4.99 \pm 0.47 and $2.33 \pm 0.36 \mathrm{~g} \mathrm{GAE} \mathrm{kg}^{-1}$, resp.), while minimum amount was determined in free phenolics of W1 $\left(2.58 \pm 0.07 \mathrm{~g} \mathrm{GAE} \mathrm{kg}^{-1}\right)$ and bound phenolics of W2 $\left(0.80 \pm 0.11 \mathrm{~g} \mathrm{GAE} \mathrm{kg}^{-1}\right)$. In B2 cultivar, free phenolics were $68.19 \%$ and bound phenolics were $31.81 \%$ of total phenolic contents. Total phenolic contents in black sesame varieties (B1, B2, and B3) ranged from 4.54 to $7.32 \mathrm{~g} \mathrm{GAE} \mathrm{kg}^{-1}$ with maximum value in $\mathrm{B} 2$, whereas among white sesame seed W3 exhibited the highest total phenolic contents of $4.04 \pm 0.13 \mathrm{~g} \mathrm{GAE} \mathrm{kg}^{-1}$, followed by W2 $\left(4.00 \pm 0.18 \mathrm{~g} \mathrm{GAE} \mathrm{kg}^{-1}\right)$ and W1 $\left(3.56 \pm 0.08 \mathrm{~g} \mathrm{GAE} \mathrm{kg}^{-1}\right)$ variety. On the whole, the black sesame varieties contain more phenolics compared to the white varieties. However, no significant differences between free, bound, and total phenolics were observed between black and white sesame varieties. Nadeem et al. [23] reported the total phenolics extracted from sesame cake were $1.72 \mathrm{~g} \mathrm{GAE} \mathrm{kg}^{-1}$. Shahidi et al. [4] reported that the total phenolic contents of two sesame seed cultivars (black and white) were $29.9 \pm 0.6$ and $10.6 \pm 1.6 \mathrm{~g}$ catechin equivalents $\mathrm{kg}^{-1}$ crude ethanolic extract, respectively. These studies were not comparable with our data for different samples (sesame cake) or reference control (catechin) used in the determination.

From Figure 1(b), the contents of free flavonoid ranged from 2.88 (B3) to 4.61 (W3) $\mathrm{gCE} \mathrm{kg}^{-1}$, and the bound flavonoids were between 2.24 (W2) and 3.52 (B2) $\mathrm{g} \mathrm{CE} \mathrm{kg}^{-1}$, while total flavonoid contents ranged from 5.80 (B3) to 8.04

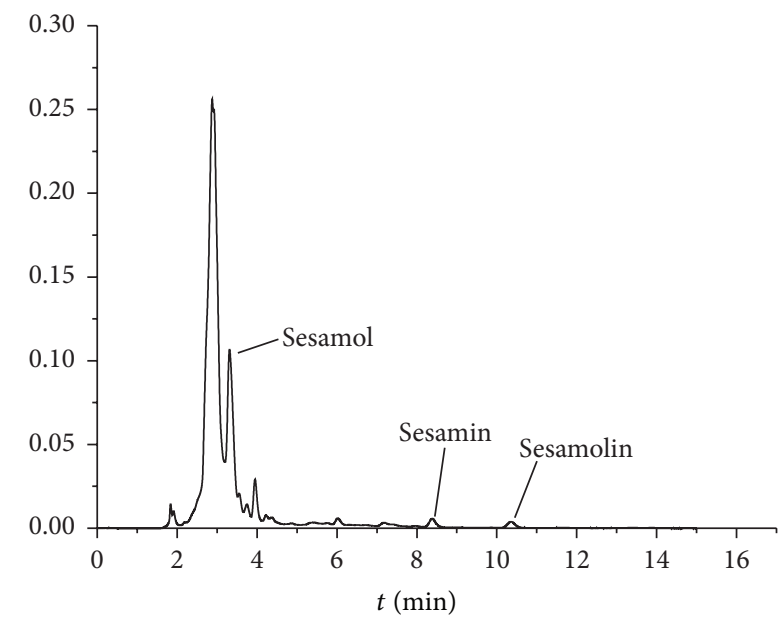

FIGURE 2: Elution curve of lignans (sesamol, sesamin, and sesamolin) of free phenolic extracts of B2 variety (mobile phase: methanol/water $75: 25$; flow rate: $1 \mathrm{~mL} \mathrm{~min}^{-1}$, wavenumber: $290 \mathrm{~nm}$; and Waters $\mathrm{C}_{18}$ column).

(W3) $\mathrm{gCE} \mathrm{kg}^{-1}$. W3 variety exhibited the highest level of total flavonoids $(8.04 \pm 0.26)$ and free flavonoids $(4.61 \pm$ 0.06) $\mathrm{g} \mathrm{CE} \mathrm{kg}^{-1}$, while the highest levels of bound flavonoids were present in $\mathrm{B} 2\left(3.52 \pm 0.08 \mathrm{~g} \mathrm{CE} \mathrm{kg}^{-1}\right)$. On the whole, no significant differences of the flavonoid contents (free, bound, and total flavonoids) were observed between black and white sesame varieties.

3.2.2. Contents of Lignans. Lignans here including sesamol, sesamin, and sesamolin in free and bound extracts of sesame seeds were analyzed by HPLC (Figure 2, Table 2). Overall, free phenolic extracts contain more levels of lignans $(>89 \%)$ 
TABLE 2: Lignans (sesamol, sesamin, and sesamolin) contents of free and bound phenolics extracts in six sesame seeds varieties.

\begin{tabular}{lccccccc}
\hline \multirow{2}{*}{ Varieties } & \multicolumn{2}{c}{ Sesamol $\left(\mathrm{mg} \mathrm{kg}^{-1}\right)$} & \multicolumn{2}{c}{ Sesamin $\left(\mathrm{mg} \mathrm{kg}^{-1}\right)$} & \multicolumn{2}{c}{ Sesamolin $\left(\mathrm{mg} \mathrm{kg}^{-1}\right)$} & \multirow{2}{*}{${\mathrm{Total}\left(\mathrm{mg} \mathrm{kg}^{-1}\right)}^{2}$} \\
& Free extracts & Bound extracts & Free extracts & Bound extracts & Free extracts & Bound extracts & ND \\
B1 & $79.21 \pm 3.62$ & $7.14 \pm 0.23$ & ND & ND & ND & N6.35 \\
B2 & $187.25 \pm 10.56$ & $30.54 \pm 2.98$ & $39.55 \pm 0.38$ & ND & $25.12 \pm 0.95$ & ND & 282.46 \\
B3 & $121.48 \pm 3.28$ & ND & $4.95 \pm 0.20$ & ND & $10.30 \pm 0.20$ & ND & 136.72 \\
W1 & $34.58 \pm 1.99$ & ND & $14.25 \pm 1.74$ & ND & $4.94 \pm 0.21$ & ND & 53.76 \\
W2 & $7.15 \pm 0.75$ & ND & $39.57 \pm 1.26$ & ND & $12.86 \pm 0.76$ & ND & 59.57 \\
W3 & $27.32 \pm 3.46$ & ND & ND & ND & $1.97 \pm 0.22$ & ND & 29.28 \\
\hline
\end{tabular}

ND means not detected.

Data were reported as mean \pm SD.

Limit of detection was $0.06 \mathrm{mg} \mathrm{kg}^{-1}$ for sesamol, $0.83 \mathrm{mg} \mathrm{kg}^{-1}$ for sesamin, and $1.01 \mathrm{mg} \mathrm{kg}^{-1}$ for sesamolin.

compared to the bound extracts. Sesamol and sesamolin contents were detected in the free extracts of all varieties. The lignans in free phenolic extracts of white and black sesame varieties ranged from 29.28 to 53.76 and 82.83 to $251.91 \mathrm{mg} \mathrm{kg}^{-1}$, respectively. The average lignan content of the three black cultivars $\left(167.34 \mathrm{mg} \mathrm{kg}^{-1}\right)$ was three times higher than that of the white cultivars $\left(47.54 \mathrm{mg} \mathrm{kg}^{-1}\right)$. B2 variety showed the highest sesamol $\left(187.25 \pm 10.56 \mathrm{mg} \mathrm{kg}^{-1}\right)$ in free phenolic extracts, followed by B3 $\left(121.48 \pm 3.28 \mathrm{mg} \mathrm{kg}^{-1}\right)$ and $\mathrm{B} 1\left(79.21 \pm 3.62 \mathrm{mg} \mathrm{kg}^{-1}\right)$. In white varieties, sesamol in free phenolic extracts ranged from $7.15 \pm 0.75$ (W2) to 34.58 $\pm 1.99 \mathrm{mg} \mathrm{kg}^{-1}$ (W1). Likewise, B2 variety had the highest sesamolin content $\left(25.12 \pm 0.95 \mathrm{mg} \mathrm{kg}^{-1}\right)$ in free phenolic extracts, followed by B3 $\left(10.30 \pm 0.20 \mathrm{mg} \mathrm{kg}^{-1}\right)$ and B1 (not detected). Sesamin was detected in the free extracts of four varieties with the highest value in W2 $\left(39.57 \pm 1.26 \mathrm{mg} \mathrm{kg}^{-1}\right)$ and B2 $\left(39.55 \pm 0.38 \mathrm{mg} \mathrm{kg}^{-1}\right)$, followed by W1 (14.25 \pm $\left.1.74 \mathrm{mg} \mathrm{kg}^{-1}\right)$ and B3 $\left(4.95 \pm 0.20 \mathrm{mg} \mathrm{kg}^{-1}\right)$. However, sesamin was not detected in bound phenolic extracts.

It has been reported [24-26] that sesamin and sesamolin contents in sesame seeds ranged from 1550 to $4200 \mathrm{mg} \mathrm{kg}^{-1}$ and 620 to $3590 \mathrm{mg} \mathrm{kg}^{-1}$, respectively. In the present study, the possible reason for lower sesamin and sesamolin contents $\left(<40 \mathrm{mg} \mathrm{kg}^{-1}\right.$ ) was the extraction solvents. Although 70 80\% methanol is common solvent for the extraction of total phenolics and flavonoids [14, 20], lipid-soluble lignans (sesamin and sesamolin) are partially soluble in $70 \%$ methanol based on visual observation. Likewise, the relatively higher content of sesamol compared to sesamin and sesamolin was observed in the free and bound extracts, which is possibly related to the relatively higher dissolving ability of sesamol in $70 \%$ methanol. Mostly previous studies were designed to determine the maximal content of lignans in sesame seeds, so the extraction organic solvents commonly used were weak polar ethanol, methanol, and acetonitrile. Here, our aim was to evaluate the lignan levels and their contribution to in vitro antioxidant activity in extracted fractions of sesame seeds, which leads to the relatively lower contents of lignans determined. Sesamin and sesamolin were successfully separated in setting chromatographic parameters (Figure 2), but the baseline separation of sesamol was not attained in the present work.
3.3. In Vitro Antioxidant Activity. Due to the complex components in sesame seeds, two in vitro antioxidant activity assays (ORAC and PSC) were used in the present study. The common principle of determination was to measure radical chain breaking ability of antioxidants by monitoring the inhibition of peroxyl radical, while different oxidantfluorescein probes were used: ABAP-fluorescein in ORAC assay and ABAP-DCFH in PSC assay $[18,20]$.

Measured values of ORAC and PSC based on DW are given in Figures 3(a) and 3(b). ORAC values ranged from 34.85 (B1) to 95.48 (W2) $\mu \mathrm{mol} \mathrm{TEg}^{-1}$ in free fractions (Figure 3(a)), while in bound fractions it was between 14.97 (W2) and 40.74 (B3) $\mu \mathrm{mol} \mathrm{TE} \mathrm{g}^{-1}$. Black sesame variety $\mathrm{B} 2$ exhibited the highest total ORAC value $\left(132.33 \mu \mathrm{mol} \mathrm{TE} \mathrm{g}{ }^{-1}\right)$, whereas B1 showed the lowest total ORAC value $\left(59.51 \mu \mathrm{mol} \mathrm{TE} \mathrm{g}^{-1}\right)$. White sesame variety $\mathrm{W} 1$ had the highest total PSC value among all varieties, which was 4 times higher than the lowest one (W2), followed by B3, B1, B2, W3, and W2 (Figure 3(b)). PSC value of free fractions ranged from 2.55 (W2) to 12.27 (B3) $\mu \mathrm{mol} \mathrm{VCE} \mathrm{g}^{-1}$, while in bound fractions it ranged from 1.33 (W3) to 6.45 (W1) $\mu \mathrm{mol} \mathrm{VCE} \mathrm{g}{ }^{-1}$. The total PSC values ranged from 4.50 (W2) to 18.55 (W1) $\mu \mathrm{mol} \mathrm{VCE} \mathrm{g}^{-1}$. Ishiyama et al. [27] reported that ORAC values of two sesame seed varieties (Japan Kanto No. 1 and Gomazou) were 658.3 and $8.27 \mathrm{mg} \mathrm{TE} \mathrm{g}^{-1}$, respectively. These values correspond to 26.30 and $33.04 \mu \mathrm{mol} \mathrm{TE} \mathrm{g}^{-1}$ of sesame seed, which was comparable to the free fractions of B1 and B3 but was nearly one-fourth to one-third of the corresponding values of varieties $\mathrm{B} 2, \mathrm{~W} 1, \mathrm{~W} 2$, and $\mathrm{W} 3$. Othman et al. [28] recently reported that the average ORAC values of polar-soluble crude extracts for white and gold sesame seed were 347.20 and $217.00 \mu \mathrm{mol} \mathrm{TE} \mathrm{g}^{-1}$, respectively. These reported data were nearly 2.6- and 1.6-fold higher than total ORAC value in B2 (the highest in this study), which verified the significant antioxidant activity of polar-soluble extracts.

Correlation analysis of the in vitro antioxidant activity with the multicomponents of selected sesame seeds was shown in Table 3. Bound ORAC values showed strong associations with contents of bound phenolics $(r=0.976$, $p<0.01)$. Moreover, total ORAC values showed strong association with contents of total phenolics $(r=0.701, p<0.01)$. 
TABLE 3: Correlation of multicomponents (phenolics, flavonoids, and lignans) with antioxidant (ORAC, PSC) and antiproliferation (EC ${ }_{50}$ ) activities of six sesame seed varieties.

\begin{tabular}{|c|c|c|c|c|c|c|c|}
\hline & Free phenolics & Bound phenolics & Total phenolics & Free flavonoids & Bound flavonoids & Total flavonoids & Lignans \\
\hline Free PSC values & -0.406 & $\mathrm{NC}$ & $\mathrm{NC}$ & -0.265 & $\mathrm{NC}$ & $\mathrm{NC}$ & $\mathrm{NC}$ \\
\hline Bound PSC values & NC & 0.604 & $\mathrm{NC}$ & $\mathrm{NC}$ & 0.294 & $\mathrm{NC}$ & $\mathrm{NC}$ \\
\hline Total PSC values & NC & NC & 0.020 & NC & $\mathrm{NC}$ & 0.130 & 0.542 \\
\hline Free ORAC values & 0.286 & $\mathrm{NC}$ & $\mathrm{NC}$ & 0.634 & $\mathrm{NC}$ & $\mathrm{NC}$ & $\mathrm{NC}$ \\
\hline Bound ORAC value & $\mathrm{NC}$ & $0.976^{* *}$ & $\mathrm{NC}$ & NC & 0.417 & $\mathrm{NC}$ & NC \\
\hline Total ORAC values & $\mathrm{NC}$ & NC & $0.701^{* *}$ & $\mathrm{NC}$ & $\mathrm{NC}$ & $0.412^{*}$ & 0.533 \\
\hline Free $\mathrm{EC}_{50}$ & -0.750 & NC & NC & 0.465 & $\mathrm{NC}$ & $\mathrm{NC}$ & $\mathrm{NC}$ \\
\hline Bound $\mathrm{EC}_{50}$ & NC & $-0.869^{*}$ & $\mathrm{NC}$ & NC & -0.666 & $\mathrm{NC}$ & NC \\
\hline
\end{tabular}

$* *$ means significant difference at $p<0.01$.

$*$ means significant difference at $p<0.05$.

NC means not computed.

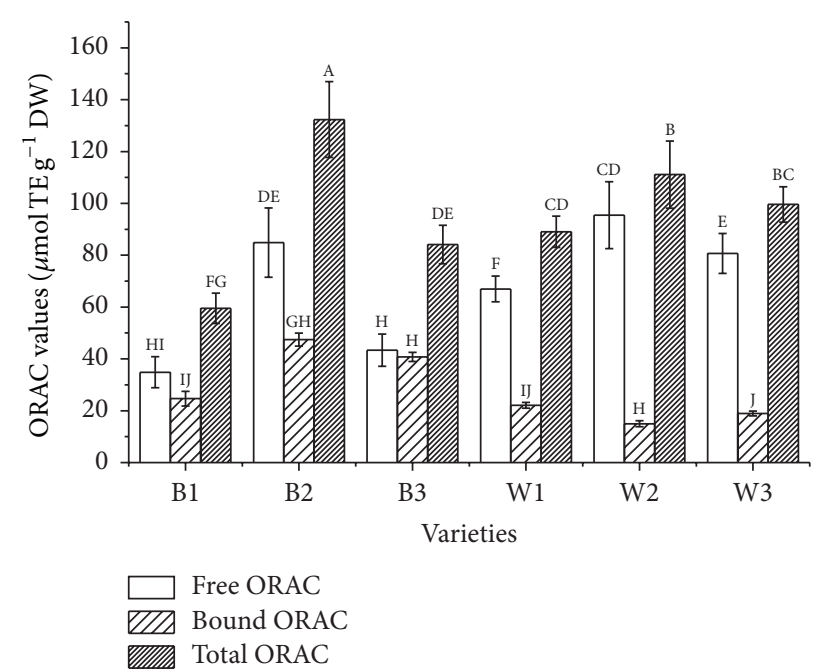

(a)

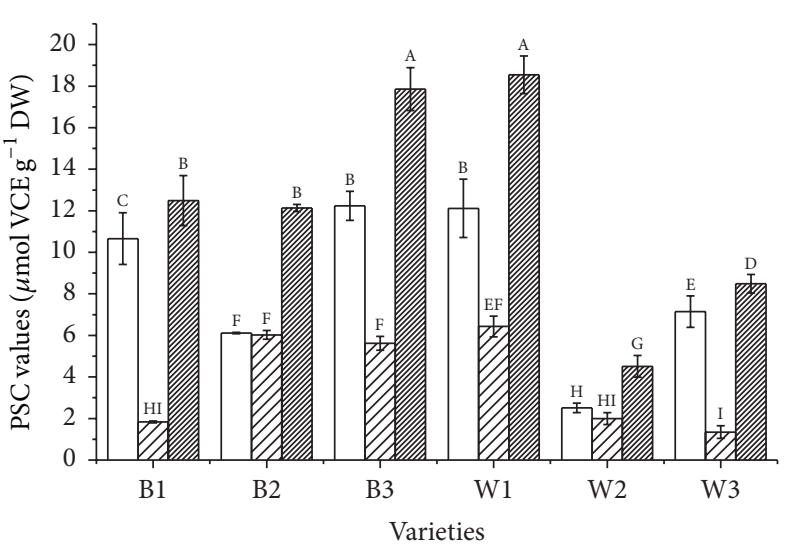

Free PSC
Bound PSC
Total PSC

(b)

FIGURE 3: In vitro antioxidant activities of six sesame seed varieties (B1, B2, B3, W1, W2, and W3) (mean \pm SD; $n=3$ ). Bars with no letters in common are significant difference at $p<0.05$. (a) ORAC values. (b) PSC value.

Moderate associations were observed between total ORAC values and contents of total flavonoids $(r=0.412, p<0.05)$. However, associations between total lignans and antioxidant activities (ORAC and PSC values) were not observed. From ORAC values of $\mathrm{B} 2, \mathrm{~W} 1, \mathrm{~W} 2$, and $\mathrm{W} 3$, PSC values of $\mathrm{B} 1, \mathrm{~B} 3$, $\mathrm{W} 1$, and $\mathrm{W} 3$, and their corresponding contents of lignans (Figure 3, Table 3), it can be inferred that the relatively higher antioxidant activities of free phenolic extracts compared to bound phenolic extracts were related to the relatively higher contents of lignans in free phenolic extracts. Comparable antioxidant activity was observed in PSC values of B2 and W2 variety and ORAC values of B2 and B3 variety in free and bound phenolic extracts (Figure 3, Table 3), even none or less lignans determined in bound phenolic extracts, which indicated that nonlignan components contribute to their corresponding antioxidant activities. There were no significant associations between PSC values (free, bound, and total) with corresponding contents of phenolic and flavonoid. Though specific reason is not clear, synergistic effects of various phytochemicals may involve complex antioxidant behavior of these constituents. Many similar reports were observed in selected components of sesame seed or sesame seed oil, such as synergistic antioxidant activity between lignans (sesamin, sesamol, sesamolin) and tocopherols ( $\alpha$, $\beta$, and $\gamma$ ) in various test system [29,30]. Except the weak polar lignan components, the water soluble extracts of sesame seed raised concern. Moazzami et al. [31] quantified lignan glucosides in 65 different sesame seed cultivars, but no significant difference between black and white seeds was observed. Othman et al. [28] reported that extracts from white sesame seed had relatively higher antioxidant capacity compared to extracts from gold sesame seeds and ascribed the possible reason to the differences in the contents of antioxidants. Ide et al. [32] compared the physiological activities of sesame seeds with different concentration of lignans in rats and found that sesame seeds rich in lignans, irrespective of composition of lignans, greatly affect hepatic fatty acid oxidation and serum triacylglycerol levels. However, the researchers stated that there is a possibility that compounds other than lignans are involved in the physiological activities of tested sesame seeds. 
TABLE 4: Antiproliferative activities of the free and bound phenolic extracts from six sesame seeds varieties against HepG2 cell.

\begin{tabular}{|c|c|c|}
\hline \multirow{2}{*}{ Varieties } & \multicolumn{2}{|c|}{ Antiproliferative capacity to $\mathrm{HepG} 2, \mathrm{EC}_{50}\left(\mathrm{mg} \mathrm{mL}^{-1}\right)$} \\
\hline & Free phenolic extract & Bound phenolic extract \\
\hline B1 & $66.08 \pm 0.35^{b}$ & $55.49 \pm 9.01^{b}$ \\
\hline B2 & $21.04 \pm 0.60^{\mathrm{a}}$ & $23.57 \pm 0.88^{\mathrm{a}}$ \\
\hline B3 & $63.45 \pm 0.85^{\mathrm{b}}$ & $30.06 \pm 0.82^{\mathrm{a}}$ \\
\hline W1 & $87.29 \pm 3.57^{\mathrm{c}}$ & $77.74 \pm 1.29^{c}$ \\
\hline W2 & $82.12 \pm 3.10^{\mathrm{c}}$ & $109.53 \pm 1.23^{\mathrm{d}}$ \\
\hline W3 & $124.91 \pm 2.79^{\mathrm{d}}$ & $67.18 \pm 1.92^{\mathrm{c}}$ \\
\hline
\end{tabular}

Data were reported as mean \pm SD.

Values in the same rows with different letters differ significantly at $p<0.05$.

These reports indicate the complex antioxidant activity of multicomponents of sesame seeds.

3.4. Antiproliferation in HepG2 Cancer Cell. Cell culture models provide efficient approach that imitates the uptake, distribution, and metabolism of antioxidant compounds in vivo [33], and human liver cancer HepG2 cell model is widely used in the antioxidant, antiproliferative activity of various compounds $[14,34,35]$. The antiproliferative effect of free and bound phenolic extracts against HepG2 cells was present in Table 4. The $\mathrm{EC}_{50}$ of free phenolic extracts ranged from $21.04 \pm 0.60$ to $124.91 \pm 2.79 \mathrm{mg} \mathrm{mL}^{-1}$ for HepG2 cells, while corresponding values for bound phenolic extracts ranged from $23.57 \pm 0.88$ to $109.53 \pm 1.23 \mathrm{mg} \mathrm{mL}^{-1}$. Lower values of $\mathrm{EC}_{50}$ indicate a higher antiproliferative activity. Both free and bound phenolic extracts of B2 variety showed antiproliferative activity. This result is consistent with the relatively higher contents of phenolics, flavonoids, and lignans and ORAC values of B2 variety. Interestingly, the black sesame seed varieties showed higher antiproliferative activity compared to the white varieties in both free phenolic and bound phenolic extracts. Moreover, in bound phenolic extracts, highly negative significant correlations were observed between $\mathrm{EC}_{50}$ and bound phenolics $(r=-0.869, p<0.05)$ and $\mathrm{EC}_{50}$ and bound ORAC values $(r=-0.918, p<0.01)$; in free phenolic extracts, highly negative significant correlations were observed between $\mathrm{EC}_{50}$ and sesamol contents $(r=$ $-0.858, p<0.05$ ) (data not shown).

Sesamin and sesamol have been reported to have anticancer activities in many cancer cell lines including HepG2. Sesamin of $25-125 \mu \mathrm{M}$ could induce HepG2 cell death involving apoptosis [36]. Content of sesamin in free phenolic extract of B2 variety was nearly $39.55 \mathrm{mg} \mathrm{kg}^{-1} \mathrm{DW}$, which is roughly equivalent to $11 \mu \mathrm{M}$ sesamin. As for sesamol, at dosage of $50 \mu \mathrm{M}$, apoptosis against HepG2 cell could be observed by Liu et al. [37], while the content of sesamol in free phenolic extracts of B2 variety was nearly $187.25 \mathrm{mg} \mathrm{kg}^{-1} \mathrm{DW}$, which is roughly equivalent to $135 \mu \mathrm{M}$ of sesamol. These results were consistent with the significant correlation observed between antiproliferation activity and content of sesamol in free phenolic extracts. Additionally, in bound phenolic extracts of B1, B2, W1, and W2 variety, contents of lignans (sesamol, sesamin, and sesamolin) were far less compared to their free phenolic extracts (Table 2). However, the corresponding antiproliferative activities in free phenolic extracts and bound phenolic extracts were comparable (Table 4). Thus, it can be inferred that the antiproliferative activities of sesame seed were not only related to the contents of phenolics and lignans (sesamol) of free phenolic extracts but also related to nonlignan components in bound phenolic extracts, which need further investigation.

\section{Conclusions}

Sesame seed variety of Fenheizhi3 (black, B2) could be more valuable than the others (Zhenzhoul, 05H27, Jizhi157, Fenzhi2, and Jizhil) based on the ex vivo antioxidant and antiproliferative activities. In selected sesame seeds, free phenolic contents were higher than the bound phenolic contents; black sesame seeds generally depicted higher contents of total phenolic compared to the white varieties. Moreover, the antioxidant activities (total ORAC values) were associated with the contents of total phenolics and flavonoids $(r>0.4$, $p<0.05$ ); the antiproliferation activities (bound $\mathrm{EC}_{50}$ ) were associated with contents of bound phenolics and sesamol $(r>0.8, p<0.05)$. Additionally, nonlignan components in bound phenolic extracts contributed to the corresponding antioxidant and antiproliferative activities.

\section{Competing Interests}

All authors declared that they have no conflict of interests.

\section{Authors' Contributions}

Lin Zhou designed and performed the experiments; Xiaohui Lin participated in the experiments; Arshad Mehmood Abbasi and Bisheng Zhen analyzed data and provided reagents, materials, and analytical tools. Lin Zhou provided financial support.

\section{Acknowledgments}

The authors are grateful for the financial support from the Fundamental Research Funds for the Central Universities (2015 D2155140) and Natural Science Foundation of Guangdong Province (44555019). Professor Rui hai Liu from Department of Food Science, Cornel University, provided technical support on the antioxidant determination.

\section{References}

[1] H. A. Abou-Gharbia, A. A. Y. Shehata, and F. Shahidi, "Effect of processing on oxidative stability and lipid classes of sesame oil," Food Research International, vol. 33, no. 5, pp. 331-340, 2000.

[2] M. Namiki, "Nutraceutical functions of sesame: a review," Critical Reviews in Food Science and Nutrition, vol. 47, no. 7, pp. 651-673, 2007.

[3] M. Elleuch, S. Besbes, O. Roiseux, C. Blecker, and H. Attia, "Quality characteristics of sesame seeds and by-products," Food Chemistry, vol. 103, no. 2, pp. 641-650, 2007. 
[4] F. Shahidi, C. M. Liyana-Pathirana, and D. S. Wall, "Antioxidant activity of white and black sesame seeds and their hull fractions," Food Chemistry, vol. 99, no. 3, pp. 478-483, 2006.

[5] H. Zhang, H. Miao, L. Wei, C. Li, R. Zhao, and C. Wang, "Genetic analysis and QTL mapping of seed coat color in sesame (Sesamum indicum L.)," PLoS ONE, vol. 8, no. 5, Article ID e63898, 2013.

[6] Y. Zuo, C. Peng, Y. Liang et al., "Sesamin extends the mean lifespan of fruit flies," Biogerontology, vol. 14, no. 2, pp. 107-119, 2013.

[7] M. Tada, Y. Ono, M. Nakai et al., "Evaluation of antioxidative effects of sesamin on the in vivo hepatic reducing abilities by a radiofrequency ESR method," Analytical Sciences, vol. 29, no. 1, pp. 89-94, 2013.

[8] M. Srisayam, N. Weerapreeyakul, S. Barusrux, and K. Kanokmedhakul, "Antioxidant, antimelanogenic, and skinprotective effect of sesamol," Journal of Cosmetic Science, vol. 65, no. 2, pp. 69-79, 2014.

[9] T. Furumoto and K. Nishimoto, "Identification of a characteristic antioxidant, anthrasesamone F, in black sesame seeds and its accumulation at different seed developmental stages," Bioscience, Biotechnology and Biochemistry, vol. 80, no. 2, pp. 350-355, 2016.

[10] D.-Z. Hsu, C.-T. Liu, P.-Y. Chu, Y.-H. Li, S. Periasamy, and M.Y. Liu, "Sesame oil attenuates ovalbumin-induced pulmonary edema and bronchial neutrophilic inflammation in mice," BioMed Research International, vol. 2013, Article ID 905670, 7 pages, 2013.

[11] P. Xu, F. Cai, X. Liu, and L. Guo, "Sesamin inhibits lipopolysaccharide-induced proliferation and invasion through the p38-MAPK and NF- $\kappa$ B signaling pathways in prostate cancer cells," Oncology Reports, vol. 33, no. 6, pp. 3117-3123, 2015.

[12] A. A. Dar and N. Arumugam, "Lignans of sesame: purification methods, biological activities and biosynthesis-a review," Bioorganic Chemistry, vol. 50, pp. 1-10, 2013.

[13] P. J. Kanu, "Biochemical analysis of black and white sesame seeds from China," American Journal of Biochemistry and Molecular Biology, vol. 1, no. 2, pp. 145-157, 2011.

[14] Y. Chen, G. Chen, X. Fu, and R.-H. Liu, "Phytochemical profiles and antioxidant activity of different varieties of Adinandra tea (Adinandra Jack)," Journal of Agricultural and Food Chemistry, vol. 63, no. 1, pp. 169-176, 2015.

[15] V. L. Singleton, R. Orthofer, and R. M. Lamuela-Raventós, "Analysis of total phenols and other oxidation substrates and antioxidants by means of Folin-Ciocalteu reagent," Methods in Enzymology, vol. 299, pp. 152-178, 1998.

[16] X. He, D. Liu, and R. H. Liu, "Sodium borohydride/chloranilbased assay for quantifying total flavonoids," Journal of Agricultural and Food Chemistry, vol. 56, no. 20, pp. 9337-9344, 2008.

[17] M. V. Reshma, C. Balachandran, C. Arumughan et al., "Extraction, separation and characterisation of sesame oil lignan for nutraceutical applications," Food Chemistry, vol. 120, no. 4, pp. 1041-1046, 2010.

[18] D. Huang, B. Ou, M. Hampsch-Woodill, J. A. Flanagan, and R. L. Prior, "High-throughput assay of oxygen radical absorbance capacity (ORAC) using a multichannel liquid handling system coupled with a microplate fluorescence reader in 96-well format," Journal of Agricultural and Food Chemistry, vol. 50, no. 16, pp. 4437-4444, 2002.

[19] M. W. Zhang, R. F. Zhang, F. X. Zhang, and R. H. Liu, "Phenolic profiles and antioxidant activity of black rice bran of different commercially available varieties," Journal of Agricultural and Food Chemistry, vol. 58, no. 13, pp. 7580-7587, 2010.

[20] K. K. Adom and R. H. Liu, "Rapid peroxyl radical scavenging capacity (PSC) assay for assessing both hydrophilic and lipophilic antioxidants," Journal of Agricultural and Food Chemistry, vol. 53, no. 17, pp. 6572-6580, 2005.

[21] D. L. Felice, J. Sun, and R. H. Liu, "A modified methylene blue assay for accurate cell counting," Journal of Functional Foods, vol. 1, no. 1, pp. 109-118, 2009.

[22] R. H. Liu, J. R. Jacob, J. H. Hotchkiss, P. J. Cote, J. L. Gerin, and B. C. Tennant, "Woodchuck hepatitis virus surface antigen induces nitric oxide synthesis in hepatocytes: possible role in hepatocarcinogenesis," Carcinogenesis, vol. 15, no. 12, pp. 28752877, 1994.

[23] M. Nadeem, C. Situ, A. Mahmud et al., "Antioxidant activity of sesame (Sesamum indicum L.) cake extract for the stabilization of olein based butter,' Journal of the American Oil Chemists' Society, vol. 91, no. 6, pp. 967-977, 2014.

[24] J. H. Kim, W. D. Seo, S. K. Lee et al., "Comparative assessment of compositional components, antioxidant effects, and lignan extractions from Korean white and black sesame (Sesamum indicum L.) seeds for different crop years," Journal of Functional Foods, vol. 7, no. 1, pp. 495-505, 2014.

[25] S. K. Kwan, S. H. Park, and M. G. Choung, "Nondestructive determination of lignans and lignan glycosides in sesame seeds by near infrared reflectance spectroscopy," Journal of Agricultural and Food Chemistry, vol. 54, no. 13, pp. 4544-4550, 2006.

[26] N. Rangkadilok, N. Pholphana, C. Mahidol et al., "Variation of sesamin, sesamolin and tocopherols in sesame (Sesamum indicum L.) seeds and oil products in Thailand," Food Chemistry, vol. 122, no. 3, pp. 724-730, 2010.

[27] K. Ishiyama, M. Nagashima, T. Yasumoto, and Y. Fukuda, "Changes in amounts of lignan compounds and radical scavenging activities in improved high-lignan breed of sesame, 'Gomazou', during germination,' Journal of the Japanese Society for Food Science and Technology, vol. 53, no. 1, pp. 8-16, 2006.

[28] S. B. Othman, N. Katsuno, Y. Kanamaru, and T. Yabe, "Watersoluble extracts from defatted sesame seed flour show antioxidant activity in vitro," Food Chemistry, vol. 175, pp. 306-314, 2015.

[29] M. Dachtler, F. H. M. Van De Put, F. V. Stijn, C. M. Beindorff, and J. Fritsche, "On-line LC-NMR-MS characterization of sesame oil extracts and assessment of their antioxidant activity," European Journal of Lipid Science and Technology, vol. 105, no. 9, pp. 488-496, 2003.

[30] Ghafoorunissa, S. Hemalatha, and M. V. V. Rao, "Sesame lignans enhance antioxidant activity of vitamin E in lipid peroxidation systems," Molecular and Cellular Biochemistry, vol. 262, no. 1-2, pp. 195-202, 2004.

[31] A. A. Moazzami, S. L. Haese, and A. Kamal-Eldin, "Lignan contents in sesame seeds and products," European Journal of Lipid Science and Technology, vol. 109, no. 10, pp. 1022-1027, 2007.

[32] T. Ide, A. Azechi, S. Kitade et al., "Comparative effects of sesame seeds differing in lignan contents and composition on fatty acid oxidation in rat liver," Journal of Oleo Science, vol. 64, no. 2, pp. 211-222, 2015.

[33] K. L. Wolfe and H. L. Rui, "Cellular antioxidant activity (CAA) assay for assessing antioxidants, foods, and dietary supplements," Journal of Agricultural and Food Chemistry, vol. 55, no. 22, pp. 8896-8907, 2007. 
[34] K. J. Meyers, C. B. Watkins, M. P. Pritts, and R. H. Liu, "Antioxidant and antiproliferative activities of strawberries," Journal of Agricultural and Food Chemistry, vol. 51, no. 23, pp. 6887-6892, 2003.

[35] L. Z. Zhang and R. H. Liu, "Phenolic and carotenoid profiles and antiproliferative activity of foxtail millet," Food Chemistry, vol. 174, pp. 495-501, 2015.

[36] P. Deng, C. Wang, L. Chen et al., "Sesamin induces cell cycle arrest and apoptosis through the inhibition of signal transducer and activator of transcription 3 signalling in human hepatocellular carcinoma cell line HepG2," Biological and Pharmaceutical Bulletin, vol. 36, no. 10, pp. 1540-1548, 2013.

[37] Z. Liu, Q. Xiang, L. Du, G. Song, Y. Wang, and X. Liu, “The interaction of sesamol with DNA and cytotoxicity, apoptosis, and localization in HepG2 cells," Food Chemistry, vol. 141, no. 1, pp. 289-296, 2013. 

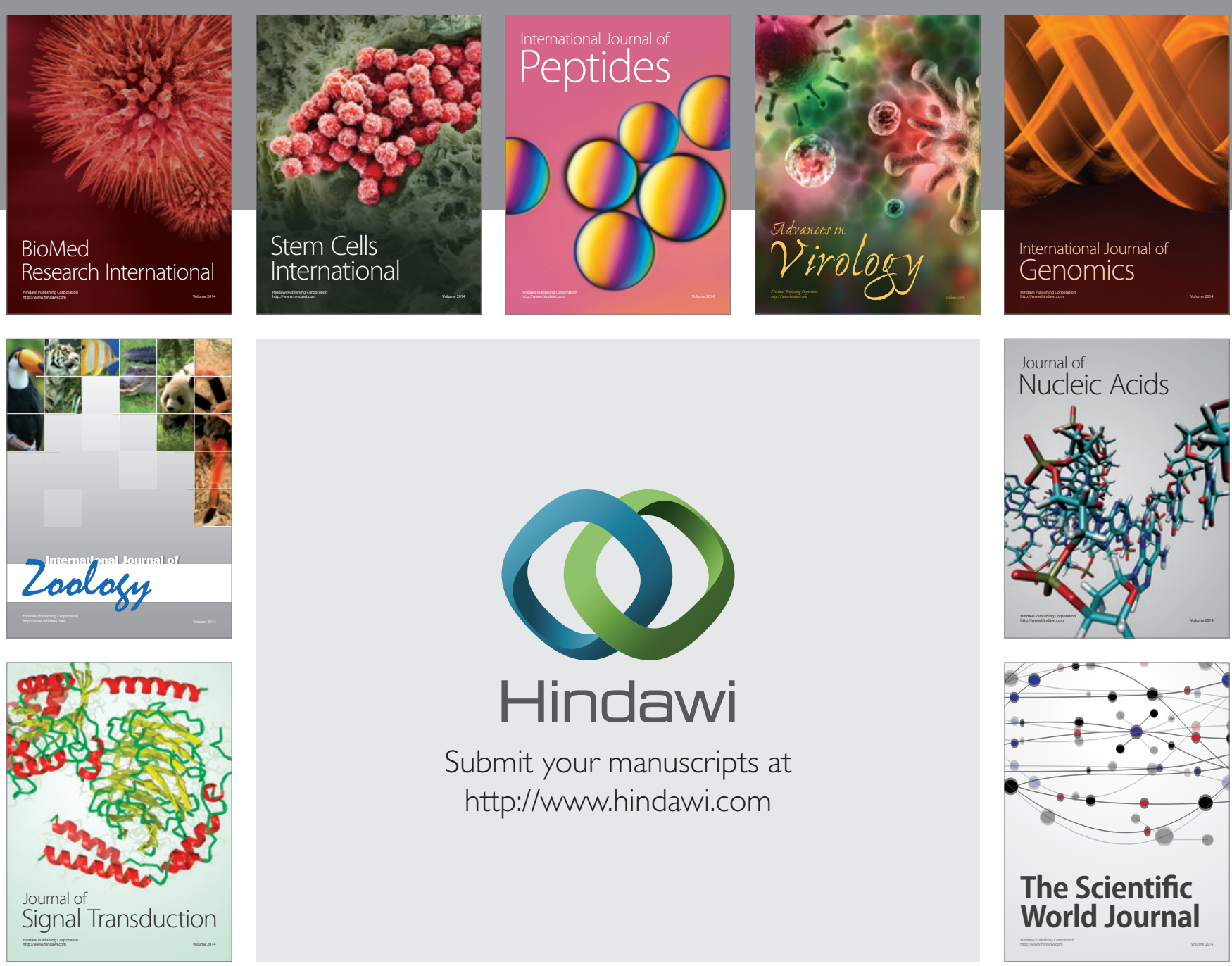

Submit your manuscripts at

http://www.hindawi.com
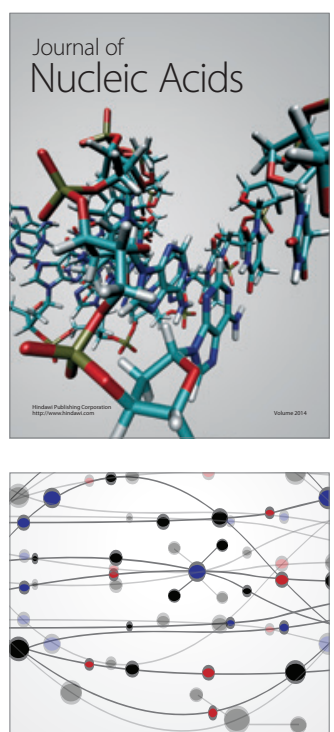

The Scientific World Journal
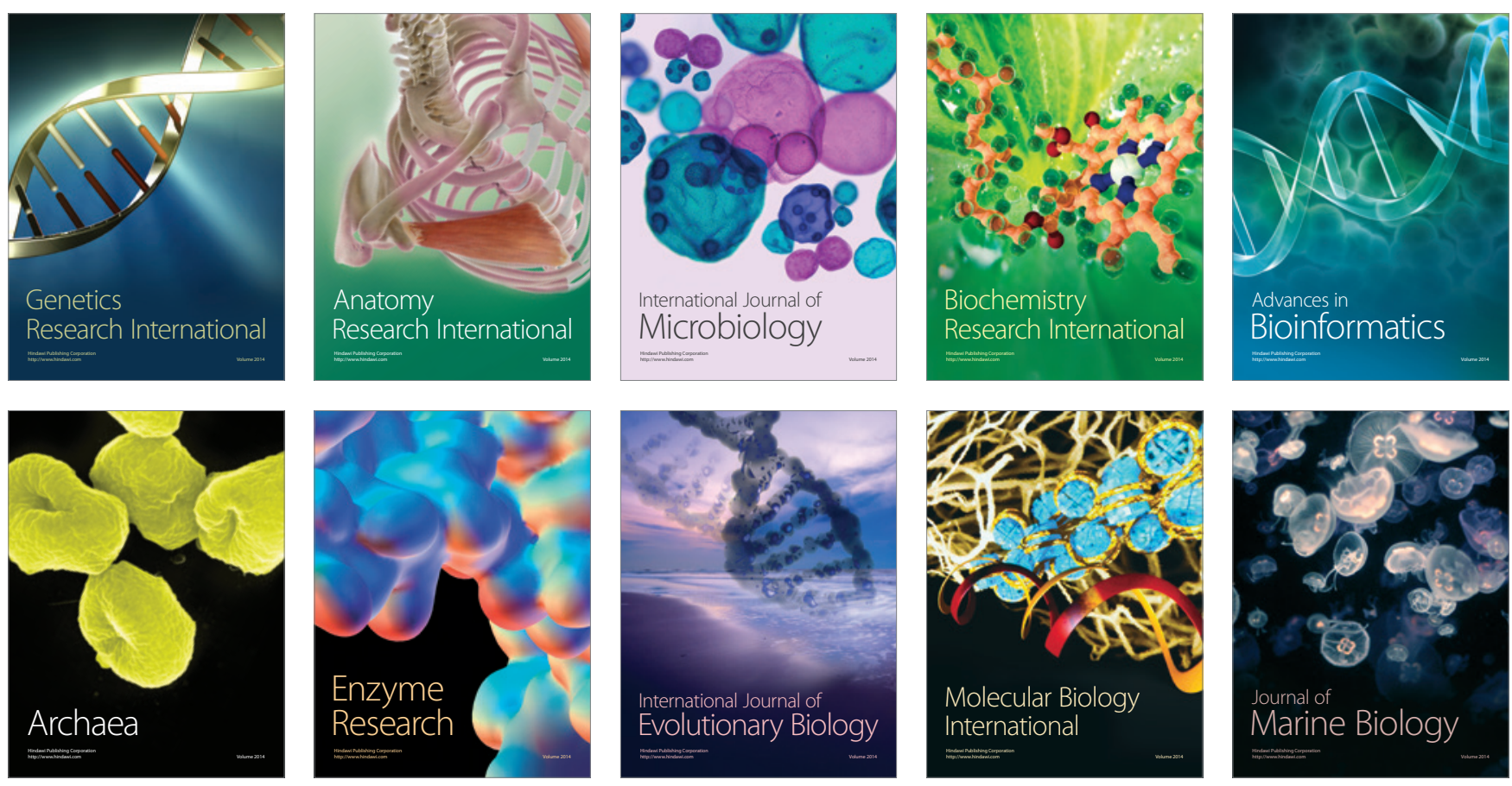